\title{
NERC RADIOCARBON AGE MEASUREMENTS DETERMINED BY RADIOMETRIC COUNTING 1996-2005
}

\author{
M H Garnett ${ }^{1,2} \cdot$ D D Harkness $^{1} \cdot$ B F Miller $^{3} \cdot$ A E Fallick $^{4} \cdot$ C L Bryant ${ }^{1}$ \\ ABSTRACT. We describe a new compilation of radiocarbon age measurements performed by the NERC Radiocarbon Lab- \\ oratory that is freely available to access over the World Wide Web. The database contains $1000{ }^{14} \mathrm{C}$ measurements performed \\ using the liquid scintillation counting method between 1996 and 2005, and further results will be added as the information is \\ compiled. Contextual information including sampling location and the nature of sample material is provided, alongside ${ }^{14} \mathrm{C}$ \\ age results and publications codes. Hypertext links provide access to the original ${ }^{14} \mathrm{C}$ age report associated with the samples, \\ providing additional details. The ${ }^{14} \mathrm{C}$ measurements were originally performed for earth and environmental science NERC \\ projects and are therefore likely to be most relevant to the Quaternary research community.
}

\section{INTRODUCTION}

Radiocarbon dating is perhaps the most widely used radiometric dating method applied in Quaternary studies (Lowe and Walker 1984), allowing precise dating of materials from varying environments and contexts up to $\sim 50,000$ yr old. For many decades after the establishment of the method, ${ }^{14} \mathrm{C}$ age results were published in "date lists" in journals such as Radiocarbon, allowing wider access to results of potential scientific value to other researchers. Although some date lists are still reported, the practice of publishing lists of ${ }^{14} \mathrm{C}$ results in scientific journals has greatly diminished, perhaps due to the greater volume of measurements that are now performed (Harkness et al. 1997).

When applied in a research project, details of the ${ }^{14} \mathrm{C}$ analyses performed are usually reported within research papers in scientific journals and are thus made publicly available. However, in some cases, important details (e.g. sample pretreatment, precise sampling location, or publication codes) may have been omitted, which limits the potential value of the results to other researchers. In further situations, ${ }^{14} \mathrm{C}$ results may not even make publication, and therefore may not have been made publicly accessible. Here, we report the provision of a Web-based database of ${ }^{14} \mathrm{C}$ measurements performed by the Natural Environment Research Council (NERC) Radiocarbon Laboratory (now NERC Radiocarbon Facility (Environment)), which we hope will provide a useful resource to scientists, particularly within the Quaternary research community.

\section{BACKGROUND}

The United Kingdom's Natural Environment Research Council established a ${ }^{14} \mathrm{C}$ laboratory at East Kilbride, near Glasgow, in 1971. In accordance with NERC's policy to "ensure that the maximum benefits are derived from data acquired by NERC" (NERC Data Policy Handbook), early ${ }^{14} \mathrm{C}$ measurements performed by the laboratory were published in date lists in the journal Radiocarbon (Harkness and Wilson 1973, 1974, 1979; Harkness 1981). In 1976, the laboratory became a NERC central facility, charged with providing a UK ${ }^{14} \mathrm{C}$ facility for earth and environmental scientists. This resulted in a substantial increase in output from the laboratory, and consequently, it was not practical to report the measurements in Radiocarbon date lists. Instead, results of analyses performed by the lab from 1977 to 1988 were subsequently collated and published as a CD-ROM in an issue of Quaternary Science Reviews (Harkness et al. 1997).

\footnotetext{
${ }^{1}$ NERC Radiocarbon Facility (Environment), Rankine Avenue, East Kilbride G75 0QF, United Kingdom. ${ }^{2}$ Corresponding author. Email: M.Garnett@nercrcl.gla.ac.uk.

${ }^{3}$ Physics and Astronomy Dept., Solid State Physics Group, University of Glasgow, Glasgow G12 8QQ, United Kingdom.

${ }^{4}$ Scottish Universities Environmental Research Centre, Rankine Avenue, East Kilbride G75 0QF, United Kingdom.
} 
Over the last 2 decades, the output of ${ }^{14} \mathrm{C}$ results from the laboratory has further increased, from a few hundred analyses per year to well over a thousand sample age measurements annually. This increase in analyses has largely been facilitated by technological advances. In the 1970s and 1980s, all ${ }^{14} \mathrm{C}$ measurements by the lab were performed by liquid scintillation counting; however, from the 1990 s measurements were increasingly made using accelerator mass spectrometry (AMS). ${ }^{14} \mathrm{C}$ measurement using liquid scintillation counting ceased at the laboratory in 2005 after the establishment of the AMS at the Scottish Universities Environmental Research Centre (SUERC), host institution of the NERC Radiocarbon Facility (Environment).

Although many papers have been published utilizing and reporting ${ }^{14} \mathrm{C}$ measurements performed by the NERC Radiocarbon Laboratory (see http://www.gla.ac.uk/nercrcl/Publications_new.htm) over the last few decades, no compendium of the laboratory's ${ }^{14} \mathrm{C}$ analyses has been produced to include the results of measurements performed since 1988. Thus, many ${ }^{14} \mathrm{C}$ measurements that are of potential scientific value to other researchers have not been made publicly available, while those that have been published are scattered across the scientific literature. In view of this, to maximize the scientific value of all NERC-sponsored ${ }^{14} \mathrm{C}$ analyses performed by the laboratory, we aim to produce a centralized database of the ${ }^{14} \mathrm{C}$ measurements that is freely and conveniently accessible via the World Wide Web. Towards this end, we have now made available results of $1000{ }^{14} \mathrm{C}$ analyses performed by the laboratory using the liquid scintillation method between 1996 and 2005. It is planned that further results, including those performed using AMS, will also be made available in the future.

\section{ACCESSING THE DATABASE OF RADIOCARBON RESULTS}

The main component of the database of ${ }^{14} \mathrm{C}$ results and associated information is provided as a spreadsheet that can be downloaded from the laboratory's Web site (http://www.gla.ac.uk/nercrcl/ results.htm). The spreadsheet contains contextual information such as sampling location and the nature of material analyzed, as well as ${ }^{14} \mathrm{C}$ age results and publication codes. We chose to present these data in a spreadsheet since it is a format that is simple and convenient to use, while also being easily searchable. Instructions on how to download the spreadsheet are provided on the Web site.

The spreadsheet can be stored locally on a user's computer, and will provide most of the information that potential users of the results will require. However, each sample record is accompanied by a hypertext link that provides access, again via the Web, to the original ${ }^{14} \mathrm{C}$ age report. It is recommended that users consult the age report since it contains important details that are not included on the spreadsheet, such as laboratory pretreatment of the samples. For convenience, age reports are provided in the widely used PDF format.

As well as the database of ${ }^{14} \mathrm{C}$ age results and associated sample details, the spreadsheet contains additional information stored on separate sheets. One sheet provides a description of the data fields in the main database. Of particular note is the "Project number," which is a unique reference associated with the original project for which the ${ }^{14} \mathrm{C}$ determinations were made. Using the Project number, users can search a list of publications, provided on a further sheet in the spreadsheet file, to see if any of the results from the project have been previously published. A fourth sheet of the spreadsheet file provides a simple summary of the sampling location for the set of $1000{ }^{14} \mathrm{C}$ samples, indicating that the samples have been grouped into 28 different locations, from across 5 continents.

\section{MEASUREMENT DETAILS AND DEFINITIONS OF REPORTED RESULTS}

All ${ }^{14} \mathrm{C}$ measurements reported in the current database were determined by radiometric counting of beta emissions (from ${ }^{14} \mathrm{C}$ decay) by liquid scintillation counting of benzene synthesized from carbon 
extracted from the original sample material (Harkness and Wilson 1972). Prior to liquid scintillation counting, samples were first pretreated to remove potential contaminants using a variety of standard processes used routinely in the preparation of ${ }^{14} \mathrm{C}$ samples (details provided in the age reports accessible by the hypertext links). Following pretreatment, the sample carbon was converted to carbon dioxide $\left(\mathrm{CO}_{2}\right)$ inside a combustion bomb under a high-pressure atmosphere of pure oxygen (organic materials), or hydrolyzed using hydrochloric acid (carbonates). Sample $\mathrm{CO}_{2}$ was cryogenically purified, and then reacted with lithium (to form lithium carbide), which was subsequently hydrolyzed, producing acetylene $\left(\mathrm{C}_{2} \mathrm{H}_{2}\right)$. Finally, the acetylene was converted to liquid benzene $\left(\mathrm{C}_{6} \mathrm{H}_{6}\right)$ on a catalyst. Measured volumes of the sample benzene were prepared with scintillator (Butyl-PBD) in vials, and then stored for 3 weeks to prevent emissions from radon decay contaminating sample ${ }^{14} \mathrm{C}$ counts. Beta emissions from ${ }^{14} \mathrm{C}$ decay were then measured on Quantulus $1220^{\mathrm{TM}}$ liquid scintillation counters (LKB Wallac, Finland). An aliquot of the sample benzene was burned-back to $\mathrm{CO}_{2}$ and measured to determine $\delta^{13} \mathrm{C}_{\mathrm{VPDB}}$ using an isotope ratio mass spectrometer (VG Optima, Micromass, UK).

Following international procedures, all ${ }^{14} \mathrm{C}$ results are reported as conventional ${ }^{14} \mathrm{C}$ ages (years before present (BP), where 0 BP represents AD 1950), calculated using the original Libby half-life for ${ }^{14} \mathrm{C}(5568 \mathrm{yr})$, and using $95 \%$ of the activity of the oxalic acid international ${ }^{14} \mathrm{C}$ standard (National Bureau of Standards, USA) for the modern reference (Stuiver and Polach 1977). Again, following standard protocols, all ${ }^{14} \mathrm{C}$ ages were normalized to a $\delta^{13} \mathrm{C}$ of $-25 \%$ using the $\delta^{13} \mathrm{C}$ of the burned-back sample $\mathrm{CO}_{2}$ (Stuiver and Polach 1977). Analytical confidence was determined for each sample based on sample counts and the analytical uncertainty of $\delta^{13} \mathrm{C}$ measurements, and following convention, expressed at the $1-\sigma$ level (representing $68 \%$ confidence).

\section{ACKNOWLEDGMENTS}

We are grateful for technical assistance from Frank Elliott, Margaret Currie, Callum Murray, and Liam Chalmers, and for administrative support from Maureen Hastings. Lin Kay (NERC Scientific Services and Facilities Management Team), and the Chairmen and members of the NERC Radiocarbon Laboratory Steering Committee (past and present) are acknowledged for providing their time and expertise to ensure maximum scientific return from the ${ }^{14} \mathrm{C}$ analyses, all of which were funded by the Natural Environment Research Council.

\section{REFERENCES}

Harkness DD. 1981. Scottish Universities Research and Reactor Centre radiocarbon measurements IV. Radiocarbon 23(2):252-304.

Harkness DD, Wilson HW. 1972. Some applications in radiocarbon measurement at the Scottish Research Reactor Centre. In: Proceedings of the 8th International Radiocarbon Conference, Wellington, New Zealand, October 1972. p B101-B115. Royal Society, New Zealand: Wellington.

Harkness DD, Wilson HW. 1973. Scottish Universities Research and Reactor Centre Radiocarbon measurements I. Radiocarbon 15(3):554-65.

Harkness DD, Wilson HW. 1974. Scottish Universities
Research and Reactor Centre Radiocarbon measurements II. Radiocarbon 16(2):238-51.

Harkness DD, Wilson HW. 1979. Scottish Universities Research and Reactor Centre Radiocarbon measurements III. Radiocarbon 21(2):203-56.

Harkness DD, Miller BF, Tipping RM. 1997. NERC radiocarbon measurements 1977-1988. Quaternary Science Reviews 16(8):925-7.

Lowe JJ, Walker MJC. 1984. Reconstructing Quaternary Environments. Longman: London. 389 p.

Stuiver M, Polach HA. 1977. Discussion: reporting of ${ }^{14} \mathrm{C}$ data. Radiocarbon 19(3):355-63. 